\title{
An Investigation into the Influence of Bank Loans Granted to Agriculture Sector on Iranian Economic Growth
}

\author{
Ali Pourmonazah \\ Auditing Chief Manager of Kargaran Refah Bank, Tehran, Iran \\ *Corresponding Author: Email: Alipourmonazzah@gmail.com
}

Doi:10.5901/mjss.2015.v6n6s2p722

\begin{abstract}
Reaching a favorable economic growth is one of the main economic targets of every society on which agricultural activities influence a lot. Iranian agriculture sector can play a positive role in national economy growth. Factors which can increase valueadded in agriculture sector receive more attention and are supported by government. Implementation of widespread economic plans in agricultural sector in developing countries like Iran requires huge investments and financial resources. Therefore, developing countries like Iran rely highly on bank credits and loans for financing agriculture activities. Therefore, the present research aims to investigate the influence of bank loans on agriculture sector and economic growth in Iran during 1991-2012. To this end, the present research investigates reliability and determines causal relationships among research variables and then makes use of VAR method for estimating research model. The results showed that bank loans and degree of economic freedom have positive impacts on economic growth in Iran in the studied period.
\end{abstract}

Keywords: bank loans, degree of economic freedom, economic growth, VAR model

\section{Introduction}

Economic growth and development is an important concern for all societies and governments. In developing countries, in particular, the need for economic growth is more important. Economic growth and development requires specific mechanisms in social, cultural and economic arenas. Powerful financial markets are among these mechanisms. In fact, monetary and financial markets are resources for crediting different economic activities. Financing production unitswhether from circulating capital viewpoint or from development of new activities and investments viewpoint-is one of the main discussions in management (Samsami and Amirjan, 2011). On the other hand, agriculture sector is one of the main production sectors in developing countries like Iran and accounts for a considerable share of gross national production. In spite of its important role in production and employment in developing countries, agriculture sector has a higher production risk in comparison with other economic activities. Because of high risk in allocation of financial resources, private and commercial banks tend to invest in other economic sectors because their main goal is to gain make profit.

Since economic resources are limited, it seems necessary to allocate resources optimally and use them efficiently in order to maximize national profit. Investment in agriculture sector is also considered as a key element for growth and development. Shortage of investment in agriculture sector reduces productivity of production inputs. Small productivity means reduction in expected income of agriculture plans and profitability. Therefore, agriculture sector is one of the sectors which has been supported by Iranian Government in the Five-year economic development programs. Iranian Government has supported agriculture sector by using different policies like giving loans, guaranteed purchase of products and so on (lotfi and Ahmadzadehmashinchi, 2007). Considering the fact that most farmers have low savings in Iran, use of bank loans is the main way for providing required capital. Loans which are granted to agriculture sector increase economic growth by increasing value added in agriculture sector. Therefore, if bank loans are used appropriately in agriculture sector, they can result in improvement of performance in agriculture production inputs and therefore increases value added in agriculture sector and economic growth (SharifiRenani et al, 2013). The main target of the present research is to investigate the influence of bank loans which were granted to agriculture sector on Iranian economic growth during 1991-2012. In fact, the author(s) would like to find whether the amount of bank loans granted to agriculture sector can improve economic growth in Iran in the studied years or not? 


\section{A Review of Agriculture Sector in Iran}

Agricultural sector is always an important economic sector and failure to pay special attention to this section can cause irreparable harms to national economy. Iran has a relative advantage in production of many agricultural products due to having potentials like having more than 37 million of hectares of land which are good for farming, having 130 billions of cubic meter of exploitable water, appropriate weather and active human force (NeginTaji and Omidi Kia, 2013). A review of agricultural indices shows that value added in this sector has experienced a growing trend during 1991-2012. In 2012, value added of agriculture sector was equal to 125120.2 billion Rials (compared to constant price in 2004). In comparison with 1991, this value indicates a growth of 70\%. Figure 1 indicates trend of value added in agriculture sector during 19912012.

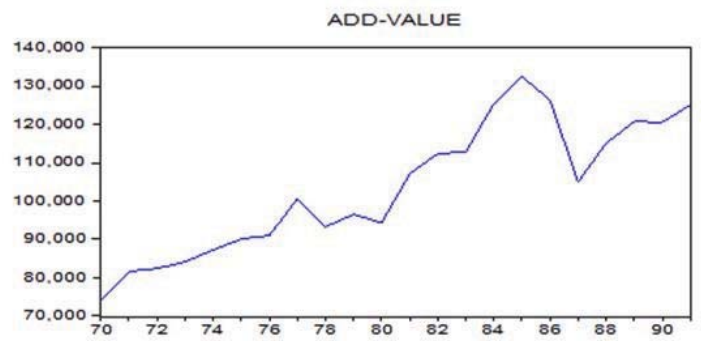

Figure 1. Trend of value added in agriculture sector in Iran during 1991-2011

Furthermore, investment in agriculture sector is one of the main factors of achieving stable economic development and growth and creation of new jobs. Average investment in agriculture sector in 1991 was equal to 5242.7 billion rials and in 2011 it was equal to 7825.4 billion rials. This shows a growth equal to $50 \%$. Financing investment activities is mainly implemented by undistributed profit and bank credits. Bank loans are the main resources for private sector investment. According to statistics of Iranian Central Banks, total bank loans amount was equal to 372734.7 in 2012 while it was equal to 2949.1 billion Rials in 1991. Figure 2 indicates trend of loans granted by banks to agriculture sector.

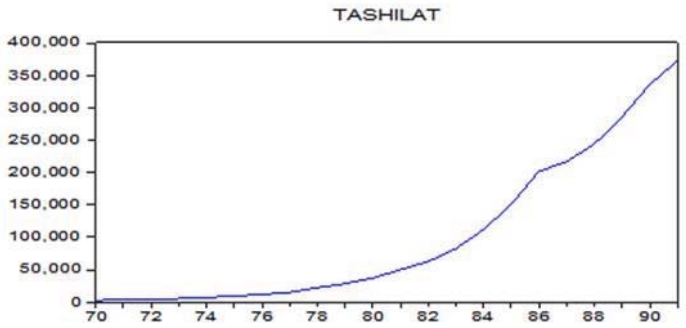

Figure 2. Trend of loans granted to agriculture sector during 1991-2011

\section{A Review of Previous Studies}

Sharifi Renani et al (2013) investigationed the influence of credits in agriculture bank $n$ value added in agriculture sector in Iran during 1979-2008. The results showed that obligation and non-obligation credits of agriculture bank have positive and significant impacts on value added in agriculture sector. Of course, the influence of obligation credits was greater than non-obligation credits.

NeginTaji and OmidiKia (2013) conducted to influence of bank loans on macro variables of agriculture sector in Iran. The results showed that the influence of current and investment credits on added value, investment and employment in agriculture sector.

Mousavi et al (2010) investigated the impacts of financial policies on value added in agriculture and industry 
sectors in Iran during 1971-2006. The results showed that the causal relationship has a direction from government costs towards added value. In other words, government costs have positive impacts on value added in agriculture sector in the short term. Furthermore, in a short period of time, government costs have positive and significant impacts on value added in industry sector and exports. Moreover, government costs have positive and significant impacts on value added in this sector.

Lotfi and Ahmadzadeh Mashin Chi (2007) investigationed the influence of loans granted by specialized banks to agriculture sector on value added in this sector. They investigated the relationship between loans granted to agriculture sector and value added in this sector during 1991-2003. Their results showed that there is a great correlation between loans granted by banks ad value added in agriculture sector.

Maureen et al (2012) conducted a research to investigate the influence of access to bank credits on economic performance in important economic sectors in Kenia during 2000-2010. They used panel data and generalized moments method (GMM). Their results showed that credits have positive impacts on GDP in different economic sectors like agriculture.

Ahmad (2011) investigated the impacts of credits on production in agriculture sector in Pakistan during 1974-2008. He used ARDL method in order to analyze data. Results showed that credits play important role in agriculture sector and credits are important for farmers who need to buy production materials. Furthermore, results showed that production increases by three factors: tractor, water well and seeds, and credit is the main source of buying these three elements.

Monge-Naranjo\& Hall (2003) investigated the influence of credits on production companies in Costa Rica during 1980-2002. They used Logit-Probit model and variables like: long-term relationship between firm and bank, ratio of bank credits to total liabilities of firm, persistence in receiving credit from bank, assets changes for repaying debts and other variables which indicate relationship between firm and bank. In the end, analyses were conducted by means of 4 systematic models and the results show that access to credits has a positive impact on performance of production companies and their employment.

\section{Research Model}

In terms of goal, the present research is an applied research and in terms of research methodology, it is a descriptive analytical study. Research library (books, journals and papers) was used for gathering contents on literature. VAR method was used for estimation of research model. Research was conducted in Iran and the studied period was 19912012. Eviews 8 software was used for estimation of model.

\section{The Model Used in this Research is as Follows}

$G=f(T, O P E N, R P U B)$

Where:

$\mathrm{G}=$ indicator of economic growth, in this research, we used logarithm of GDP for indicating this variable. follows:

Open: economic degree of freedom which is defined as ratio of sum of exports and imports over GDP and is as

Open $=(E X+I M) / G D P$

RPUB=population rate and Growth rate

$\mathrm{T}=$ loans granted to agriculture sector by banks

\section{Model Estimation}

\subsection{Reliability test}

Most usually, reliability of variables or randomness of time series of variables results in falsity of estimated regression. Therefore, before testing research hypotheses, we should test whether model variables are reliable with degrees 1 or zero because we want to use VAR method for estimation and necessary condition for using VAR model is testing reliability hypotheses. Therefore, we should first conduct a reliability test for research variables. to this end, Generalized Dickey-Fuller's test was used. The results of this test are presented in table 1. According to this table, all variables are reliable with degrees 1 and zero. 
Table 1: The results of unit root test in level and first-rank subtraction of variables

\begin{tabular}{|l|c|c|c|l|}
\hline Result & Certainty Level & Critical Value & Generalized Dicky-Fuller's statistic & Variable \\
\hline unreliable & $95 \%$ & -1.96 & 4.27 & Logarithm of GDP \\
\hline reliable & $90 \%$ & -1.96 & -1.83 & First rank subtraction of GDP \\
\hline reliable & $95 \%$ & -1.96 & -3.17 & Degree of economic freedom \\
\hline reliable & $90 \%$ & -1.96 & -1.78 & Population growth rate \\
\hline unreliable & $95 \%$ & -1.96 & -0.84 & Loans granted to agriculture sector \\
\hline reliable & $95 \%$ & -1.96 & -4.42 & $\begin{array}{l}\text { First-rank subtraction of loans granted } \\
\text { to agriculture sector }\end{array}$ \\
\hline
\end{tabular}

\subsection{Granger's causality}

Although regression analysis indicates dependence of a variable on other variables but it does not refer to presence of causality or cause and effect relationship. Therefore, we used Engle-Granger causality test. Mutual Granger causality test was conducted on research variables and the results are summarized in table 2.

Table 2. The results of causality test for research variables

\begin{tabular}{|l|c|c|}
\hline H0 & Prob. & F statistic \\
\hline Degree of economic freedom is not Granger causality of growth. & 0.6040 & 0.27866 \\
\hline Growth is not a Granger cause for economic freedom degree. & 0.2470 & 1.43148 \\
\hline Population growth is not a Granger cause for growth. & 0.4294 & 0.65342 \\
\hline Growth is not a Granger cause for population growth. & 0.0068 & 9.33122 \\
\hline Loans granted to agriculture sector is not a Granger cause for growth. & 0.0130 & 7.60184 \\
\hline Growth is not a Granger cause for loans granted to agriculture sector. & 0.0130 & 7.59630 \\
\hline
\end{tabular}

As it can be seen in table 2, there is no causal relationship between economic freedom degree and economic growth in Iran. About the case of population growth rate, there is also a single-direction causal relationship from economic growth towards population growth rate. However, there is a mutual causal relationship between remainder of loans granted $(T)$ and economic growth.

\subsection{Estimation of VAR model}

Determination of the number of optimal lags is necessary in vector autoregression model (VAR). we should rely on principle of frugality due to numerous parameters in VAR models. In order to determine the number of optimal lags, different criteria like likelihood ratio (LR), Akaike information criterion (AIC), Shwarts-Beizin (SBC) and Henan-Quin (HQ). Therefore, we first deal with optimal lag. The results are summarized in table 3.

Table 3. Results of determination of the number of optimal lags in research model

\begin{tabular}{|c|c|c|c|c|c|c|}
\hline HQ & SC & AIC & FPE & LR & LogL & Lag \\
\hline-4.676587 & -4.520809 & -4.719766 & $1.05 \mathrm{e}-7$ & NA & 53.55754 & 0 \\
\hline$-12.92167^{\star}$ & $-12.14278^{\star}$ & $-13.13757^{\star}$ & $2.40 \mathrm{e}-11^{\star}$ & $159.0657^{\star}$ & 157.9444 & 1 \\
\hline
\end{tabular}

Considering the results of determination of optimal lags in table 3 , the optimal lag is equal to 1 .

After investigation of reliability of research variables and determination of optimal lag, the model can be estimated by VAR method. The best model fit for factors affecting economic growth are as follows:

$\mathrm{G}=7.84+0.35 \mathrm{G}(-1)+0.12 \mathrm{~T}(-1)+0.34$ OPEN $(-1)-0.005$ RPUB $(-1)$
(3.58) (1.91)
$(3.65)$
$(2.26)$
$(-0.15)$

$\mathrm{R}^{2}=0.99$

The statistic in the parentheses is t statistic.

In the aforementioned model, all variables are statistically significant except for population growth variable. Therefore, considering the results of estimation of the model for factors affecting economic growth by means of (VAR) method, the following analysis can be made: 
1. The results of regression indicate that more than $99 \%$ of variations in economic growth is explained by model variables. According to econometrics literature, a high value for $\mathrm{R}^{2}$ is indicative of good model fit.

2. Remainder of the loans granted by banks to agriculture sector has a positive and significant influence on economic growth in Iran. as this ratio increases by $1 \%$, economic growth is increased by $12 \%$.

\subsection{Instantaneous response analysis}

After estimation, the most important stage is investigation of mutual relationships among model variables. Considering the subject, the impacts of shocks of remainder loans variables on agriculture sector, degree of economic freedom and population growth rate is investigated.

Figure 3 indicates dynamic response of economic growth variable in relation to shocks of research variables. In this figure, the horizontal axis indicates time and vertical axis indicates deviation from primary value.

Response of LOGGDP to $T$

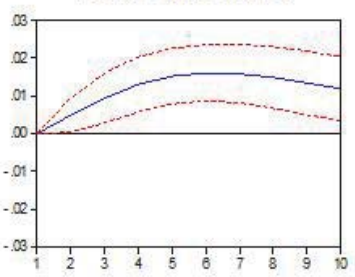

Response of LOGGDP to OPEN

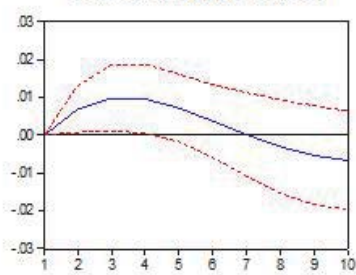

Response of LOGGDP to RPUB

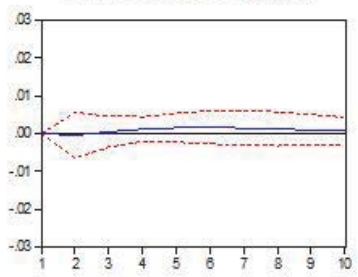

Figure 3. Dynamic response of economic growth variable in relation to research variables shocks

Figure 3 indicates that shocks exerted to population growth rate and remainder of loans granted by banks to agriculture sector in a 10-year period of time increased economic growth in Iran. however, shocks exerted to degree of economic freedom in a 10-year period of time increased economic growth in Iran and after the seventh year, it has caused decrease in economic growth.

While functions depict response of shock impact stimulation of an indogeneous variable on other variables of VAR model, variance analysis indicates changes in an indogenous varuable in relation to other indogenous variables shocks. In this method, shares of shocks exerted to different variables of the model in variance of prediction error of a variable are predicted in short term and long term. In prediction error variance, share of variations of each variuable in relation to the exerted shock is divided by model variables. therefore, we will be able to measure the share of each variable in variance of other variables over time. Variance analyses have been defined such that usually variations of each variable is explained by impulses of that variable in the first period (in short term) but shares of other variables are increased in prediction of behavior of a variable considering their importances in the long run. Table 4 indicates the results of model variance analysis. In this table, the first column indicates a 10-year analysis period and the second column indicates prediction error in prediction horizon. The resource for this kind of prediction error is variations in future and present values of shocks exerted to endogenous variables of VAR model. Considering the fact that this prediction error is calculated based on the error of the previous year, it is increased during the period of time. The subsequent columns indicate prediction variance percentage due to different shocks and sum of each column should be equal to $100 \%$. According to the results, gradually as the number of periods increase, the share of economic growth shock is reduced and share of shocks of remainder of loans granted by banks to agriculture sector and degree of economic freedom is increased. The share of population growth rate is almost constant during time.

Table 4: Variance analysis of economic growth

\begin{tabular}{|c|c|c|c|c|c|}
\hline Period & S.E. & G & T & OPEN & RPUB \\
\hline 1 & 0.027909 & 100 & 0 & 0 & 0 \\
\hline 2 & 0.033098 & 93.47 & 2.16 & 4.34 & 0.02 \\
\hline 3 & 0.036161 & 80.30 & 8.65 & 11.004 & 0.03 \\
\hline 4 & 0.039748 & 67.12 & 17.87 & 14.89 & 0.11 \\
\hline
\end{tabular}




\begin{tabular}{|c|c|c|c|c|c|}
\hline 5 & 0.044051 & 58.53 & 26.47 & 14.77 & 0.21 \\
\hline 6 & 0.048414 & 53.93 & 32.95 & 12.82 & 0.28 \\
\hline 7 & 0.052262 & 51.19 & 37.47 & 11.006 & 0.32 \\
\hline 8 & 0.055364 & 48.97 & 40.57 & 10.11 & 0.337 \\
\hline 9 & 0.057744 & 46.82 & 42.68 & 10.15 & 0.335 \\
\hline 10 & 0.059548 & 44.75 & 44.09 & 10.81 & 0.32 \\
\hline
\end{tabular}

\section{Conclusion}

Granting loans is an important part of banking operations. Banks provide credits from people who want to take part in economic activities to individuals who require financial resources for doing economic activities. In other words, banks use their credit and financial policies and can facilitate economic growth and development. Conversely, absence of giving loans can result in economic recession.

The study investigated the role of loans granted by banks to agriculture sector in economic growth in Iran using VAR method during 1991-2011. To this end, we first investigated the degree of stability of all variables using generalized Dicky-Fuller's test. The results of this test showed that some variables have zero degree and some variables are static in degree 1. Hence, Granger test was used for investigation of causality relationship between research variables. the results of causality test showed that there is a mutual relationship between remainder of bank loans granted to agriculture sector and economic growth and there is a one-way relationship from economic growth to population growth rate. The results of model estimation using VAR method showed that the influence of remainder of loans and degree of economic freedom on economic growth in Iran were positive and significant in the studied period. However, the influence of population growth rate in Iran on economic growth was not statistically significant.

According to the results, the followings can be recommended:

1. Since the results of model estimation in the studied period showed that there is a positive relationship between remainder of loans and economic growth, banks are advised to provide more loans for farmers in order to develop agricultural activities and increase economic growth.

2. The present research was conducted in a time period to investigate the influence of remainder of loansgranted to agriculture sector on economic growth. Future studies are proposed to use other time periods and investigate their impacts on economic growth in Iran.

\section{References}

Ahmad ,N. (2011). Impact of institutional credit on agricultural output: A case study of Pakistan, Theoreticaland Applied Economics, 10 (563) : 5-16.

Islamic Republic of Iran Central Bank, economic report and balance of years 1991-2012

Lotfi, Hosein and AhmadzadehMashinchi, Sina (2007), investigation of the influence of credits granted by banks to agriculture sector on value added in agricultures ector, the sixth conference on aa economy in Mashhad Ferdosi University, pp: 1-15.

Maureen, W. \&Nzomoi J. \&Rutto, N. (2012). Assessing the Impact of Private Sector Credit on Economic Performance: Evidence from Sectoral Panel Data for Kenya, International Journal of Economics and Finance, Vol 4, № 3.

MongeNaranjo, Alexander and Luis J. Hall (2003). Access to Credit and the effect of Credit Constraints on Costarican manufacturing Firms Februarg, Working Paper.

Mousavi, nematollah, Muhammadi, Hamid and Akbari, Muhammad Reza (2010), investigation of the impacts of financial policies on value added in agriculture and industry sectors in Iran; agriculture economy studies, volume 2, number 4, pp: 121-134.

NeginTaji, Zarir and OmidiKia, Mehdi (2013), the influence of bank loans on macrovariables in agricultures ector, quarterly of economic modeling, seventh year, number 4, pp: 71-87.

Saeedi, parviz and Abbasi, Ibrahim (2011), the influence of commercial banks loans on economic growth; management quarterly, eigth year, number 23, pp: 14-22.

Shah Abadi, Abolfazl and Mahmoudi, Hosein (2010), investigation of relationship between development of financial mediators and value added in Iranian agriculture sector; journal of agricultural development and economy, volume 24, number 4, pp: 496-508.

SharfiRenani, Hosein and tavakkoli, Amir and Honarvar, Naghmeh (2013), influence of credits of agriculture bank on value added in Iranian agriculture sector, quarterly of agriculture economy and development, $21^{\text {st }}$ year, number 84, pp: 205-227.

Samsami, Hosein and Amirjan, Reza (2011), investigation of the impact of bank loans on value added in industry and mining sector, quarterly of economic studies and policies, 19th year, number 59, pp: 129-150. 